\title{
Georges Ohnet, Filmographie
}

\section{Daniel Compère}

Université de la Sorbonne Nouvelle, Paris III

daniel.compere@orange.fr

Rebut: 15 de gener de 2015

Acceptat: 24 d'abril de 2015

RESUM

Georges Ohnet, filmografia

Elaboració del llistat de pel-lícules que s'han realitzat sobre les novel-les d'aquest autor.

Paraules Clau

Pel-lícula, Georges Ohnet.

RÉSUMÉ

Georges Ohnet, filmographie

Elaboration de la liste de films tirés des romans de cet auteur.

MoTS CLÉ

Film, Georges Ohnet.

RESUMEN

Georges Ohnet, filmografía

Elaboración de la lista de películas realizadas a partir de las novelas de este autor.

Palabras Clave

Película, Georges Ohnet.

AbSTRACT

Georges Ohnet, Filmography

Development of the list of films from novels by this author.

KEYWORDS

Film, Georges Ohnet. 


\section{L'Âme de Pierre}

- The Soul of Pierre, réal. Tarvers Vale (1915)

\section{La Comtesse Sarah}

- La Comtesse Sarah, réal. Henri Pouctal (Fr.), 1912.

- La Contessa Sara, réal. Roberto Roberti (It.), 1919.

\section{La Dame en gris}

- La Dame en gris, réal. Gian Paolo Rosmino (It.), 1919.

\section{Les Dames de Croix-Mort}

- Les Dames de Croix-Mort, réal. Maurice Mariaud (F.), 1919.

\section{Dernier amour}

- Letzte Liebe, réal. Hubert Moest (All.), 1919.

- Dernier amour, réal. Jean Stelli (Fr.), avec Annabella, Georges Marchal, Jeanne Moreau, Suzanne Flon, 1949.

\section{Dette de haine}

- Dette de haine, réal. Henri Pouctal (F.), 1915.

- Heilige oder Dirne, réal. Martin Berger (All.), 1929.

\section{Le Docteur Rameau}

- Dr. Rameau, réal. Will S. Davis (1915)

- My Friend the Devil, réal. Harry F. Millarde (USA), 1922.

\section{Le Droit de l'enfant}

- Le Droit de l'enfant, réal. Henri Pouctal (Fr.), 1914.

- Le Droit de l'enfant, réal. Jacques Daroy (Fr.), 1949. 


\section{La Fin d'un joueur}

- La Fin d'un joueur, réal. André Calmettes et Henri Etiévant (Fr.), 1911.

\section{La Grande marnière}

- La Grande marnière, réal. Henri Pouctal (F.), 1911.

- La Grande marniera, réal. Gero Zambuto (It.), 1920.

- La Grande marnière, réal. Jean de Marguenat (It.), 1943.

\section{Le Maître de forges}

- Gerval, le Maître de forges, réal. Henri Pouctal (F.), 1912.

- The Iron master, réal. Travers Vale (USA), 1914.

- Volonté, réal. Henri Pouctal (F.), 1917.

- American Methods, réal. Frank Lloyd (USA), 1917.

- A vasgyaros, réal. Jenö Janovics (Hongrie), 1917.

- Il Padrone delle ferriere, réal. Eugenio Perego (It.), 1919.

- The Iron master, réal. Chester M. Franflin (USA), 1933.

- Le Maître de forges, réal. Abel Gance (F.), 1933.

- El Herrero, réal. Ramón Pereda (Mexique), 1944.

- Le Maître de forges, réal. Fernand Rivers (F.), 1948.

- Il Padrone delle ferriere, réal. Anton Giulio Majano (It.), 1959.

- Tamirci parçasi, réal. Türker Inanoglu (Turquie), 1965.

- To ftohopaido, réal. Giorgos Papakostas (Grèce), 1965.

- Eho dikaioma na s'agapo !, réal. Apostolos Tegopoulos (Grèce), 1966.

- Poly arga gia dakrya, réal. Panos Glykofrydis (Grèce), 1968.

- Yarali kalp, réal. Remzi Jöntürk (Turquie), 1969.

- Les Amours de la belle époque : $1^{\mathrm{er}}$ épisode, Le maître de forges, 1979.

\section{Mauvais sentier}

- Mauvais sentier, réal. Ubaldo Pittei (It.), 1917.

\section{Nemrod et Cie}

- Nemrod et Cie, réal. Maurice Mariaud (F.), 1916. 


\section{Philippe Derblay}

- Felipe Derblay, réal. Ricardo López Aranda (Esp.), 1967.

\section{Le Roi de Paris}

- Korol Parizha, réal. Evgueni Bauer et Olga Rakhmanova (URSS), 1917.

- Le Roi de Paris, réal. Maurice de Marsan et Charles Maudru (F.), 1923.

- Le Roi de Paris, réal. Leo Mittler (All.), 1930.

\section{Serge Panine}

- Serge Panine, réal. Henri Pouctal (F.), 1913.

- Serge Panine, réal. Wray Bartlett Physioc (USA), 1915.

- Zhizn za zhizn, réal. Evgueni Bauer (Russie), 1916.

- Serge Panine, réal. Maurice de Marsan et Charles Maudru (F.), 1922.

- Serge Panine, réal. Charles Méré et Paul Schiller (Fr.), avec Françoise Rosay, Pierre Renoir, Sylvia Bataille, 1939.

\section{La Ténébreuse}

- Woman of Mystery, réal. Travers Vale (1915). 